\title{
Intestinal smooth muscle dysfunction after intraperitoneal injection of zymosan in the rat: are oxygen radicals involved?
}

\author{
A van der Vliet, $\mathrm{K}$ I van der Poel, A Bast
}

\begin{abstract}
Zymosan is frequently used as an activator of granulocytes to study inflammatory responses. We used zymosan as a model to understand the mechanisms involved in intestinal inflammatory diseases, and our special interest was focused on the smooth muscle function. Moreover, we investigated the role of oxidative stress in intestinal pathology after inflammatory processes. Intraperitoneal injection of zymosan induces a peritoneal inflammation, characterised by exudate in the peritoneum and peritoneal fibrosis. Three days after injection of zymosan ( $25-40 \mathrm{mg} / 100 \mathrm{~g}$ ) we measured a decreased $\beta$ adrenergic smooth muscle response, while the muscarinic receptor-mediated contraction was not significantly affected. Efforts were made to correlate these observations with the development of oxidative stress; however, the intestinal glutathione balance remained undisturbed and no increase in lipid peroxidation products in the intestine was observed. Our conclusion is that peritoneal inflammation will lead to a release of various mediators, which may destroy receptor systems, among which are $\beta$ adrenoceptors. There was no evidence of an important role for reactive oxygen metabolites in this effect.
\end{abstract}

Several diseases of the gastrointestinal tract are accompanied by the production of reactive oxygen metabolites. Oxygen radicals are supposed to be responsible for gastrointestinal damage after ischaemia and reperfusion. ${ }^{1+}$ In this process oxygen radicals are produced by two different mechanisms. At first reactive oxygen metabolites can be formed by xanthine oxidase, which metabolises hypoxanthine and xanthine with the use of molecular oxygen as electron acceptor, resulting in production of superoxide anions. ${ }^{56}$ Secondly, intestinal ischaemia and reperfusion cause an inflammatory response, characterised by infiltration of neutrophils into the ischaemic tissue, ${ }^{7}$ which also leads to formation of oxygen radicals. It is hypothesised that the infiltrated neutrophils give the major contribution to mucosal injury after intestinal ischaemia and reperfusion. ${ }^{8}$ Also, in other inflammatory diseases of the intestine oxygen radicals are supposed to contribute to the development of tissue damage. ${ }^{910}$ Reactive oxygen species also seem to be involved in duodenal ulceration."

Inflammation of the intestine can lead to alterations of intestinal motility, ${ }^{12-14}$ but the nature of these alterations is variable. Motility changes are also reported as a consequence of enteric infection. ${ }^{15}$ Enteric infections can induce inflammatory responses, associated with infiltration of granulocytes into the intestinal mucosa, thereby leading to mucosal injury. ${ }^{17}$

In previous studies we investigated the effect of reactive oxygen species on the intestinal smooth muscle in vitro, and we tried to establish the mechanism by which the smooth muscle function is altered. Both hydrogen peroxide and cumene hydroperoxide are capable of reducing smooth muscle responses upon contracting or relaxing agents. The effect on smooth muscle contraction was not clearly elucidated, although the membrane receptor is not likely to be selectively affected by either hydrogen peroxide or cumene hydroperoxide. ${ }^{18}$ Lipid peroxidation seems to be responsible for decreased smooth muscle function after oxidative stress in vitro. ${ }^{19}$ The $\beta$ adrenergic relaxation of intestinal smooth muscle is also vulnerable to oxidative stress. Moreover, similar to the findings in heart tissue, the effect on the $\beta$ adrenoceptor seems to be more selective..$^{2021}$

In this study we tried to validate the in vitro effects of oxidative stress on intestinal smooth muscle in an inflammation model, and investigated the effect of an inflammatory response on smooth muscle and the possible role of reactive oxygen species in this. To this end we used zymosan as an inducer of in vivo inflammation, ${ }^{22-24}$ which might affect the intestine. We found that after intraperitoneal injection of zymosan the $\beta$ adrenergic response of the small intestinal smooth muscle was reduced, but no clear evidence was found for the involvement of oxidative stress in this effect. We hypothesise that zymosan injected intraperitoneally activates intraperitoneal macrophages, leading to release of various mediators which could be harmful to some intestinal smooth muscle functions.

\section{Methods}

\section{CHEMICALS AND DRUGS}

Zymosan A, methacholine, (-)-isoprenaline, oxidised and reduced glutathione, o-phthalaldehyde, hexadecyltrimethylammonium bromide (HTAB), 3,3',5,5'-tetramethylbenzidine (TMB), forskolin, $\mathrm{N}^{6}-2^{\prime}$-O-dibutyryladenosine $3^{\prime}: 5^{\prime}$-cyclic monophosphate (sodium salt) (dibutyryl-cAMP), phenylmethylsulphonyl fluoride (PMSF), dithiothreitol, and thiobarbituric acid (TBA) were purchased from Sigma Chemical (St Louis, USA). May-Grünwald and Giemsa solutions were obtained from Merck (Darmstadt, Germany). A cyclic adenosine 
monophosphate (cAMP) assay kit (code TRK 432) was obtained from Amersham.

\section{IN VIVO STUDIES WITH ZYMOSAN}

\section{Pretreatment with zymosan}

Male albino Wistar rats weighing 200-220 g (Harlan CPB, Zeist, The Netherlands) were used. Zymosan was suspended in physiological salt solution and disinfected by heating for 30 minutes at $95^{\circ} \mathrm{C}$. After the suspension was cooled rats were given 25 or $40 \mathrm{mg}$ zymosan/100 g body weight or vehicle intraperitoneally in a maximal volume of $2 \mathrm{ml}$. Three days (72 hours) after injection the rats were killed by decapitation and about $20 \mathrm{~cm}$ of the jejunum were rapidly excised. After flushing the intraluminal contents the major part of the intestine were immersed in liquid nitrogen and stored at $-70^{\circ} \mathrm{C}$ until use. Another part was used directly for pharmacological studies or cAMP determinations.

\section{Pharmacological experiments}

Isolated segments of the small intestine $(1.5 \mathrm{~cm})$ were mounted longitudinally in $20 \mathrm{ml}$ tissue baths under $0.5 \mathrm{~g}$ of tension and kept in Krebs medium (composition in mmol: $\mathrm{NaCl} 118, \mathrm{KCl}$ 5.6, $\mathrm{MgSO}_{4} 1 \cdot 2, \mathrm{CaCl}_{2} 2 \cdot 5, \mathrm{NaH}_{2} \mathrm{PO}_{4} 1 \cdot 3$, $\mathrm{NaHCO}_{3}$ 25, and glucose 6.1), which was oxygenated with $95 \% \mathrm{O}_{2} / 5 \% \mathrm{CO}_{2}$ and kept at $37^{\circ} \mathrm{C}(\mathrm{pH} \mathrm{7} \cdot 4)$.

Smooth muscle responses were recorded isotonically. Contraction of the longitudinal smooth muscle was induced by the cumulative addition of the muscarinic agonist methacholine. ${ }^{18}$ Smooth muscle relaxation was measured by the cumulative addition of isoprenaline, which relaxes the intestinal smooth muscle from its basal tone via $\beta$ adrenoceptors. ${ }^{25}$ The activity of methacholine or isoprenaline was expressed as $\mathrm{p}\left(\mathrm{EC}_{50}\right)$. The maximal relaxation by isoprenaline was related to the relaxation induced by 0.5 $\mathrm{mmol} / \mathrm{l}$ of the stable cAMP analogue dibutyrylcAMP, which was added to a maximal responsive isoprenaline concentration. ${ }^{20}$

\section{cAMP measurements}

Pieces of intestine were cut open lengthwise and the mucosa was removed with a spatula. ${ }^{18}$ The remaining muscular tissue was homogenised in 10 volumes of $50 \mathrm{mmol} / \mathrm{l} \mathrm{Na}$ phosphate buffer (pH 7.4) including $1 \mathrm{mmol} / \mathrm{PMSF}, 10 \mathrm{mmol} / \mathrm{l}$ dithiothreitol, and $0.1 \mathrm{mmol} / \mathrm{l}$ ethylenediamine tetra-acetic acid (EDTA). The homogenate was centrifuged at $500 \mathrm{~g}$ for 5 minutes and the remaining supernatant was subsequently centrifuged at $35000 \mathrm{~g}$ for 20 minutes. The pellet was resuspended in phosphate buffer containing $0 \cdot 1$ $\mathrm{mmol} / \mathrm{l}$ EDTA until the protein concentration was $1-2 \mathrm{mg} / \mathrm{ml}$, frozen in liquid nitrogen, and stored at $-70^{\circ} \mathrm{C}$

Aliquots of intestinal membranes were incubated in Tris buffer (composition: $50 \mathrm{mmol} / \mathrm{l}$ Tris, $140 \mathrm{mmol} / \mathrm{l} \mathrm{NaCl}$, and $5 \mathrm{mmol} / 1 \mathrm{MgCl}_{2}, \mathrm{pH}$ $7 \cdot 4)$ at $37^{\circ} \mathrm{C}$ in the presence of various stimuli and $1 \mathrm{mmol} / \mathrm{l}$ adenosine triphosphate for 15 minutes. After heating and centrifugation of the precipi- tate ( 5 minutes, $200 \mathrm{~g}$ ), the supernatants were assayed for cAMP using a cAMP assay kit (Amersham). The production of cAMP was related to the protein concentration in the membrane fractions. Because of variations between separate experiments, cAMP production was expressed relatively to the basal cAMP production in membranes from control animals.

Determination of reduced and oxidised glutathione Segments of intestine were homogenised in 10 volumes of $50 \mathrm{mmol} / \mathrm{l}$ phosphate buffer $(\mathrm{pH} 7 \cdot 4)$. After precipitation of the protein with TCA oxidised and reduced glutathione were determined as described by Hissin and Hilf. ${ }^{26}$

\section{Measurement of lipid peroxidation}

Lipid peroxidation products were measured as the formation of TBA reactive material. ${ }^{27} \mathrm{We}$ homogenised segments of intestine in 10 volumes of $1 \cdot 15 \% \mathrm{KCl}$ and incubated $300 \mu \mathrm{l}$ of homogenate in $2 \mathrm{ml} \mathrm{TBA}$ containing reagent at $95^{\circ} \mathrm{C}$ for 30 minutes. Formation of TBA reactive material was measured spectrophotometrically at $535 \mathrm{~nm}$.

\section{Myeloperoxidase assay}

Infiltration of neutrophils into the intestinal mucosa was determined by measurement of tissue associated myeloperoxidase. ${ }^{28}$ Segments of intestine were homogenised in 10 volumes of 50 mmol/l sodium phosphate buffer $(\mathrm{pH} \mathrm{7 \cdot 4)}$ and centrifuged ( 20 minutes, $16000 \mathrm{~g}$ ). The pellet, which contains over $95 \%$ of the total tissue myeloperoxidase activity, was resuspended in an equal volume of potassium phosphate buffer $(\mathrm{pH}$ 6.0) containing $0.5 \% \mathrm{HTAB}$ as detergent. After another centrifugation step (20 minutes, 16000 $g$ ) the supernatant was used for myeloperoxidase assay using $\mathrm{TMB}^{29}$ Briefly, aliquots of supernatant were incubated for varying periods with $1.6 \mathrm{mmol} / \mathrm{l}$ TMB and $0.3 \mathrm{mmol} / \mathrm{l}$ hydrogen peroxide in $80 \mathrm{mmol} / \mathrm{l}$ sodium phosphate $(\mathrm{pH}$ 5.4 ) with $60 \mathrm{mmol} / 1 \mathrm{NaCl}$ in a total volume of 500 $\mu \mathrm{l}$. The reaction was terminated by the addition of $1.75 \mathrm{ml}$ of $200 \mathrm{mmol} / \mathrm{l}$ sodium acetate buffer (pH 3.0). The reaction product was measured spectrophotometrically at $655 \mathrm{~nm}$. Activities were expressed as the initial velocity of absorbance increase, which is linear during the first two minutes, at $655 \mathrm{~nm}\left(\Delta \mathrm{A}_{655} / \mathrm{min}\right)$ per $\mathrm{mg}$ of protein which was measured in the supernatant.

\section{Histological study}

Cross sections of small intestine of treated and untreated rats were made and stained with MayGrünwald solution for 10 minutes with Giemsa solution for 20 minutes. After staining the preparations were examined with light microscopy for neutrophil infiltration or general intestinal damage.

\section{Protein determination}

Protein was determined according to Bradford 
using the BioRad assay with bovine serum albumin as protein standard..$^{30}$

\section{IN VITRO STUDIES WITH ZYMOSAN}

Preparation of opsonised zymosan

Serum was obtained from male Wistar rats. Some $20 \mathrm{mg} / \mathrm{ml}$ zymosan A was suspended in Krebs buffer and heated for 30 minutes at $95^{\circ} \mathrm{C}$. After centrifugation ( 7 minutes, $175 \mathrm{~g}$ ) the pellet was resuspended in $50 \%$ serum in Krebs buffer and incubated for 30 minutes at $37^{\circ} \mathrm{C}$. Subsequently the suspension was again centrifuged ( 7 minutes, $175 \mathrm{~g}$ ) and the pellet was washed free of serum twice with Krebs buffer and suspended at a final concentration of $20 \mathrm{mg} / \mathrm{ml}$. This suspension was frozen in liquid nitrogen and stored at $-70^{\circ} \mathrm{C}$.

\section{Hydrogen peroxide production by zymosan}

The production of hydrogen peroxide by zymosan was assessed by the hydrogen peroxide dependent horseradish peroxidase catalysed oxidation of phenol red. ${ }^{31}$ The intestine was homogenised and incubated in $10 \mathrm{mmol} / 1$ potassium phosphate buffer ( $\mathrm{pH} 7 \cdot 0$ ), containing 140 $\mathrm{mmol} / \mathrm{l} \mathrm{NaCl}$, and $5.5 \mathrm{mmol} / \mathrm{l}$ glucose with 0.14 $\mathrm{mmol} / \mathrm{l}$ phenol red and $4.3 \mathrm{U} / \mathrm{ml}$ horseradish peroxidase with various amounts of (opsonised) zymosan for various periods. After incubation 10 $\mu \mathrm{l} / \mathrm{ml}$ of $1 \mathrm{~N} \mathrm{NaOH}$ was added and the mixture centrifuged ( 15 minutes, $15000 \mathrm{~g}$ ). Absorbance was measured at $610 \mathrm{~nm}$. Sodium azide $(2 \mathrm{mmol} /$ 1) was used to inhibit disproportionate distribution of hydrogen peroxide by catalase or myeloperoxidase.

\section{Pharmacological measurements}

Segments of intestine were mounted in $20 \mathrm{ml}$ tissue baths as described above. After a control concentration-response curve for isoprenaline was completed non-opsonised or opsonised zymosan was added to the tissue baths. After incubation with zymosan the organs were washed three times in buffer for 15 minutes each time and subsequently a second concentrationresponse curve for isoprenaline was recorded. The responses were related to the maximal response to isoprenaline before incubation.

STATISTICAL ANALYSIS

Differences between groups were determined

TABLE I Effect of zymosan on muscarinic and adrenergic response in the rat small intestinal smooth muscle (mean (SD))

\begin{tabular}{|c|c|c|c|}
\hline \multirow[b]{2}{*}{ Treatment } & \multirow{2}{*}{$\begin{array}{l}\text { Methacholine } \\
p\left(E C_{50}\right)\end{array}$} & \multicolumn{2}{|l|}{ Isoprenaline } \\
\hline & & $p\left(E C_{50}\right)$ & Maximal effect (\%) \\
\hline $\begin{array}{l}\text { Control } \\
25 \mathrm{mg} / 100 \mathrm{~g} \\
40 \mathrm{mg} / 100 \mathrm{~g}\end{array}$ & $\begin{array}{l}6.53(0.22)(n=7) \\
6.32(0.21)(n=4) \\
6.55(0.11)(n=3)\end{array}$ & $\begin{array}{l}6.59(0.16)(n=7) \\
6.28(0.23)(n=4)^{\star} \\
6.26(0.12)(n=4) \dagger\end{array}$ & $\begin{array}{l}72 \cdot 4(5 \cdot 6)(n=7) \\
60 \cdot 3(10 \cdot 0)(n=4)^{\star} \\
39 \cdot 4(15 \cdot 7)(n=4) \ddagger\end{array}$ \\
\hline
\end{tabular}

using Student's $t$ test with a p value of 0.05 as the limit of significance.

\section{Results}

GENERAL EFFECTS OF ZYMOSAN IN VIVO

Treatment of rats with zymosan intraperitoneally leads to peritoneal inflammation characterised by exudate in the peritoneum and peritoneal fibrosis with massive adhesions. Moreover, the rats treated with zymosan lost about $10 \mathrm{~g}$ of weight in 72 hours, while control animals grew normally (about $20 \mathrm{~g}$ ). Two of the six rats treated with the highest zymosan dose $(40 \mathrm{mg} / 100 \mathrm{~g})$ died within 72 hours. Therefore the experiments were continued with a lower dose of zymosan $(25 \mathrm{mg} / 100 \mathrm{~g})$.

\section{EFFECTS OF INTRAPERITONEAL ZYMOSAN ON} INTESTINAL SMOOTH MUSCLE FUNCTION After treatment with zymosan for 72 hours, the small intestine was isolated and pharmacological responses were established in vitro. Contractility of the intestinal smooth muscle was measured by the dose dependent contraction of the longitudinal smooth muscle by the muscarinic agonist methacholine. Table I shows that zymosan treatment did not affect the $\mathrm{p}\left(\mathrm{EC}_{50}\right)$ of methacholine and also that the maximal response to methacholine is not clearly affected by zymosan. No clear changes could be discerned on the spontaneous contractions of the intestinal segments after zymosan treatment (not shown).

Relaxation of the intestinal smooth muscle was studied with the $\beta$ adrenergic agonist isoprenaline. The $\mathrm{p}\left(\mathrm{EC}_{50}\right)$ for isoprenaline decreased slightly after zymosan treatment (Table I). The maximal relaxation by isoprenaline, which was expressed relatively to the relaxation by 0.5 $\mathrm{mmol} / \mathrm{l}$ of the stable cAMP analogue dibutyrylcAMP, was also decreased significantly (Table I and Fig 1).

This might imply that the production of cAMP by stimulation with isoprenaline is decreased. We assessed cAMP production in intestinal membranes by stimulation of the $\beta$ receptor system at various levels - namely, with $\mathrm{NaF}$ and forskolin, which stimulate the G-

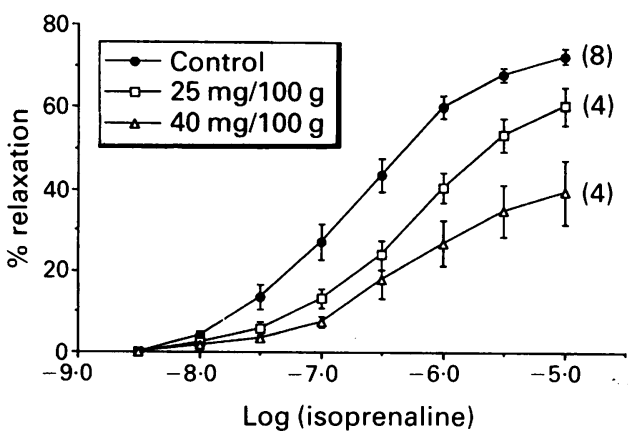

Figure 1: Concentration-response curves for (-)-isoprenaline on longitudinal jejunal segments from control rats treated with intraperitoneal zymosan for 72 hours at the indicated doses. The responses of each concentration of $(-)$-isoprenaline were expressed relatively to the response of $0.5 \mathrm{mmol} / \mathrm{l}$ dibutyryl-cAMP which was added at the completion of a concentration-response curve. Means (SEM) of the indicated number of rats are shown. 
TABLE II Effect of intraperitoneal zymosan on cAMP accumulation in rat small intestinal smooth muscle membranes by various stimuli. Number of animals given

\begin{tabular}{lcc}
\hline Stimulus & Control & Zymosan \\
\hline Basal & $100(31)(\mathrm{n}=6)$ & $59(41)(\mathrm{n}=6)$ \\
$10^{-2} \mathrm{~mol} / \mathrm{l} \mathrm{NaF}$ & $1189(226)(\mathrm{n}=4)$ & $702(286)(\mathrm{n}=6)^{\star}$ \\
$10^{-4} \mathrm{~mol} / \mathrm{l}$ forskolin & $388(141)(\mathrm{n}=5)$ & $349(121)(\mathrm{n}=6)$ \\
\hline
\end{tabular}

Intestinal membranes were prepared from rats 72 hours after intraperitoneal injection of $25 \mathrm{mg} / 100 \mathrm{~g}$ zymosan or vehicle (control) as described under Methods. Aliquots of intestinal membranes were incubated with the various stimuli for 15 membranes were incubated with the various stimuli for 15 minutes. Production of cAMP was corrected for the protein concentration in the membrane fraction. Means (SD) are shown from three separate experiments performed in duplicate. In each separate experiment the mean basal cAMP production from membranes from two untreated animals was set at $100 \%$, and all values of individual animals were expressed relatively to this mean value. The number of animals are shown between parentheses. ${ }^{\star} \mathrm{p}<0.05$ compared to corresponding control.

TABLE III Effect of zymosan treatment on oxidised and reduced glutathione and myeloperoxidase activity. Number of rats given. Mean (SD)

\begin{tabular}{lcc}
\hline & Control & Zymosan \\
\hline $\begin{array}{l}\text { Glutathione: } \\
\text { Reduced (nmol/g tissue) }\end{array}$ & $1074(272)(\mathrm{n}=3)$ & $1143(154)(\mathrm{n}=3)$ \\
$\begin{array}{l}\text { Oxidised (nmol/g tissue) } \\
\text { Myeloperoxidase (U/mg protein) }\end{array}$ & $342(22)(\mathrm{n}=3)$ & $286(32)(\mathrm{n}=3)$ \\
$4 \cdot 7(1 \cdot 1)(\mathrm{n}=4)$ & $4 \cdot 2(2 \cdot 2)(\mathrm{n}=4)$ \\
\hline $\begin{array}{l}\text { Rats were pretreated with } 25 \mathrm{mg} / 100 \mathrm{~g} \text { zymosan for } 72 \text { hours. Subsequently the small intestine was } \\
\text { isolated and assayed for reduced and oxidised glutathione and myeloperoxidase as described under }\end{array}$ \\
$\begin{array}{l}\text { Methods. No significant differences were observed between control and zymosan-treated animals for } \\
\text { glutathione content or myeloperoxidase activity. }\end{array}$
\end{tabular}
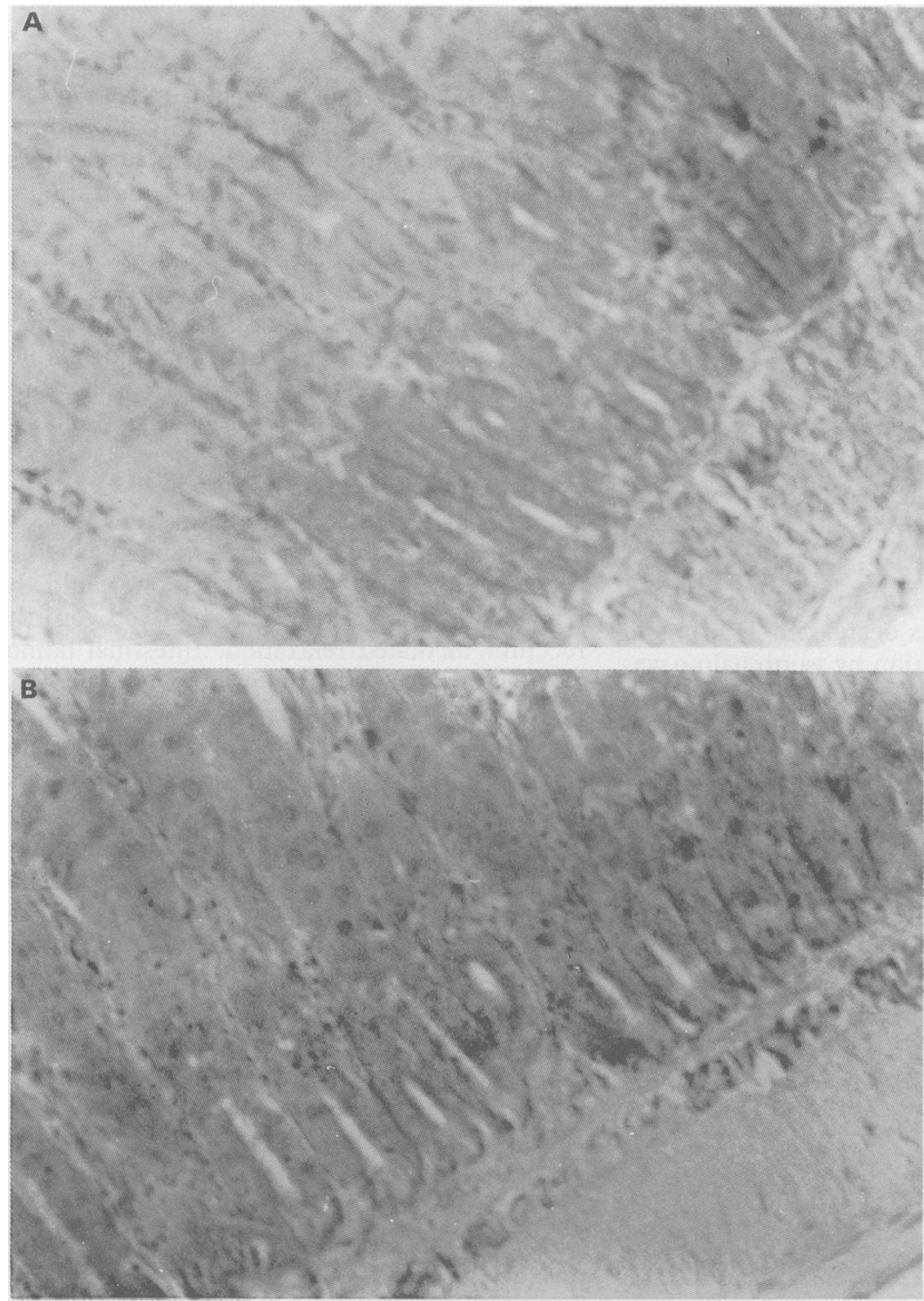

Figure 2: Light microscopy of $7 \mu m$ cross sections of the small intestine from an untreated rat $(A)$ and from a rat 72 hours after intraperitoneal injection of $25 \mathrm{mg} / 100 \mathrm{~g}$ zymosan $(B)$ after MayGrünwald/Giemsa staining. No clear infiltration of granulocytes nor substantial morphological alterations could be discovered in the intestine of zymosan treated rats. protein and adenylate cyclase respectively. Table II shows that after treatment with zymosan the production of cAMP by $\mathrm{NaF}$ is significantly decreased. Also the basal cAMP production seems to be reduced after treatment with zymosan but the difference is not significant. Forskolin stimulated cAMP production, however, is not reduced in zymosan treated animals (Table II).

\section{OXIDATIVE STRESS AFTER ZYMOSAN TREATMENT}

IN VIVO

Inflammatory processes are generally associated with oxidative stress. We therefore investigated the possible presence of oxidative stress phenomena after treatment with zymosan. Intestinal inflammation is characterised by an increased number of neutrophils in the tissue, which can be quantified by measuring the neutrophilic enzyme myeloperoxidase. Intestinal myeloperoxidase activity was, however, not increased after 72 hours of zymosan treatment (Table III). Moreover, light microscopy of cross sections of the intestine indicates that there is no visible infiltration of neutrophils in the intestinal tissue three days after treatment with zymosan. In addition, no clear morphological changes can be found after zymosan treatment (Fig 2).

Two parameters of oxidative stress were measured in this study - namely, glutathione levels and lipid peroxidation products. Table III shows that 72 hours of zymosan treatment did not lead to significant alterations in reduced or oxidised glutathione levels. Moreover, no increase was found in TBA-reactive material in the intestine of zymosan treated animals (not shown).

\section{EFFECTS OF ZYMOSAN TREATMENT IN VITRO}

From published reports it is known that opsonised zymosan is capable of stimulating the respiratory burst in neutrophils directly. ${ }^{32} \mathrm{We}$ studied the production of hydrogen peroxide by zymosan and opsonised zymosan in rat intestinal homogenates. Figure 3 shows that opsonised zymosan in contrast to zymosan leads to increased production of hydrogen peroxide in a concentration dependent manner. This implies that only opsonised zymosan stimulates an oxidative burst, whereas non-opsonised zymosan does not.

We studied the in vitro effects of zymosan and opsonised zymosan on isolated intestinal segments. However, at a concentration which stimulates hydrogen peroxide production opsonised zymosan did not affect smooth muscle relaxation by isoprenaline. Both the $\mathrm{p}\left(\mathrm{EC}_{50}\right)$ and the maximal response remained unaffected (Table IV). The isoprenaline response also was unchanged after incubation with non-opsonised zymosan (Table IV).

\section{Discussion}

Treatment of rats with intraperitoneal zymosan induces peritoneal inflammation similar to that described earlier. ${ }^{22}$ When injected, zymosan also induces an inflammatory response in other 


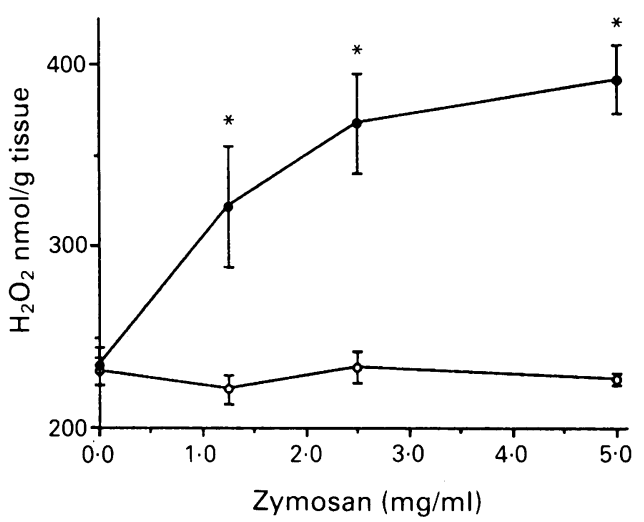

Figure 3: Generation of hydrogen peroxide by rat small intestinal homogenates after stimulation with nonopsonised $(\bigcirc)$ and opsonised (O) zymosan. Only opsonised zymosan induced a significant increase in hydrogen peroxide production. Hydrogen peroxide was measured by horseradish peroxidase catalysed oxidation of phenol red as described under Methods. Means (SEM). from rats are shown. ${ }^{\star}$ Different compared with stimulation with non-opsonised zymosan $(p<0 \cdot 05)$.

animal species, ${ }^{2324}$ characterised by a rapid increased neutrophil and macrophage number in the peritoneal cavity. Several hours after zymosan injection mainly neutrophils were affected; at later stages the number of macrophages increased..$^{2+} \mathrm{We}$ used this model to induce an inflammatory response in the intestine, and especially the intestinal smooth muscle. Three days after injection of zymosan intestinal smooth muscle function was established. In earlier experiments with in vitro oxidative stress the major effect on muscarinic smooth muscle contraction was a decrease in the $\mathrm{p}\left(\mathrm{EC}_{50}\right) \cdot{ }^{18}$ Also the $\beta$ adrenoceptor response is altered after oxidative stress in vitro. ${ }^{21}$

The muscarinic contraction induced by methacholine was not affected by zymosan treatment, since the $\mathrm{p}\left(\mathrm{EC}_{50}\right)$ for methacholine was not altered, and also the maximal response was unchanged. The $\beta$ adrenergic relaxation of the intestinal smooth muscle was, however, decreased three days after intraperitoneal injection of zymosan. The $\mathrm{p}\left(\mathrm{EC}_{50}\right)$ for the $\beta$ agonist isoprenaline was decreased slightly and also the maximal relaxation by isoprenaline was decreased compared with the maximal relaxation obtained by adding $0.5 \mathrm{mmol} / \mathrm{l}$ of the stable cAMP analogue dibutyryl-cAMP. This indicates that zymosan somehow affects $\beta$ adrenoceptor mediated formation of cAMP. We assessed the accumulation of cAMP in intestinal membranes of zymosan treated and untreated rats. Indeed,

TABLE IV Effect of (opsonised) zymosan on $\beta$ adrenergic response in vitro

\begin{tabular}{lll}
\hline Treatment & $p\left(E C_{50}\right)$ & $\begin{array}{l}\text { Maximal } \\
\text { response }(\%)\end{array}$ \\
\hline Control & $6 \cdot 8(0 \cdot 2)$ & $119(12)$ \\
Zymosan & & \\
$0.5 \mathrm{mg} / \mathrm{ml}$ & $6.9(0 \cdot 2)$ & $102(12)$ \\
$\begin{array}{l}\text { Opsonised zymosan } \\
0.5 \mathrm{mg} / \mathrm{ml}\end{array}$ & $6.6(0 \cdot 2)$ & $112(7)$ \\
$1.0 \mathrm{mg} / \mathrm{ml}$ & $6.9(0 \cdot 2)$ & $121(9)$ \\
\hline
\end{tabular}

Mean (SD) values of calculated $\mathrm{p}\left(\mathrm{EC}_{50}\right)$ and maximal responses after in vitro incubation with (opsonised) zymosan for 90 minute are presented. The maximal response was related to the maximal response to isoprenaline before incubation with (opsonised) zymosan which was set at $100 \%$.
cAMP production in intestinal membranes stimulated with $10^{-2} \mathrm{~mol} / \mathrm{l} \mathrm{NaF}$ (at this concentration the cAMP production is maximal) was significantly lower in membranes from rats treated with zymosan. We did not find a decreased forskolin stimulated cAMP production in intestinal membranes from rats treated with zymosan compared with control animals, which indicates that this treatment probably affects the $\beta$ adrenoceptor system before the adenylate cyclase unit. The receptor itself could be affected or the activity of the coupling G-proteins might be decreased. Since the $\beta$ adrenoceptor on the rat small intestinal smooth muscle is atypical ${ }^{25}$ and no suitable receptor binding assay exists for this receptor subtype, we cannot determine whether zymosan treatment affects the $\beta$ receptor population directly, but this is not unlikely.

Our next option was to determine if these effects could be related to the occurrence of oxidative stress, and we tried to detect some markers of oxidative stress in the intestinal tissue. However, oxidative stress could not be found by a decreased intestinal reduced glutathione level or an increased oxidised glutathione level, not by an increase in lipid peroxidation products.

Moreover, no evidence could be found for an increased infiltration of neutrophils in the intestinal tissue. Histological study of zymosan treated rat intestine did not show clear modification of intestinal morphology nor infiltration of neutrophils in the intestine. Moreover, no significant increased myeloperoxidase activity was observed in the intestine from rats treated with zymosan, which implies that intraperitoneal injection of zymosan does not induce symptoms like intestinal inflammation, in which infiltration of inflammatory cells is commonly observed and confirmed by increased tissue associated myeloperoxidase activity. ${ }^{17} 28$

Since non-inflamed intestinal mucosa also contains neutrophils, we investigated whether these neutrophils upon activation could be responsible for the observed effects on the receptor mediated relaxation. Intestinal homogenates are capable of producing hydrogen peroxide when stimulated with opsonised zymosan. Zymosan which is not opsonised is not capable of stimulating the respiratory burst directly ${ }^{32}$ and did not induce hydrogen peroxide production in our system. Although zymosan is not able to induce an oxidative burst in inflammatory cells directly, zymosan injected intraperitoneally might be able to cause indirect oxygen radical production. Interestingly, zymosan has been shown to induce superoxide release in rat Kupffer cells, ${ }^{33}$ indicating that also non-opsonised zymosan induced release of reactive oxygen species in some systems.

We investigated whether stimulation of the respiratory burst in intestinal neutrophils leads to alterations of the $\beta$ adrenergic response by treatment of isolated intestinal segments with (opsonised) zymosan, but we found no changes caused by normal zymosan nor by opsonised zymosan in the $\beta$ adrenergic response. This indicates that radical production induced by opsonised zymosan may be insufficient in our 
system, or that produced radicals will be scavenged or metabolised before they are able to induce damage to the smooth muscle and the $\beta$ adrenoceptor system. Moreover, it can be concluded from this that the decreased $\beta$ adrenergic response after intraperitoneal zymosan is not induced by activated mucosal neutrophils, but predominantly by peritoneal macrophages and neutrophils.

Peritoneal macrophages, activated after zymosan injection, may produce a variety of inflammatory mediators and possibly oxygen radicals, which may be responsible for the observed effects in our study. This might be correlated with the effects of in vitro oxidative stress by exogenous application of hydrogen peroxide to the small intestine. In this case the adrenergic response to isoprenaline was also decreased compared with the maximal response to dibutyryl-cAMP. ${ }^{21}$ Since no proof was found for oxidative stress in the intestine after injection or zymosan, an important role of oxygen radicals in the observed effects is not likely. However, in a previous study we found that hydrogen peroxide was also unable to induce lipid peroxidation in intestinal tissue, ${ }^{19}$ implying that oxidant production by peritoneal macrophages does not itself induce lipid peroxidation processes in the intestine. Inflammatory cells release a variety of other mediators upon stimulation, which could also be directly responsible for decreased receptor responses in the surrounding tissue. ${ }^{3+}$

The results in this study show that treatment of rats with zymosan for 72 hours induces a peritoneal but not an intestinal inflammation. The intestinal longitudinal smooth muscular $\beta$ adrenoceptor function is decreased by this treatment, which is probably not caused by oxidative stress but may due to the release of other mediators by activated peritoneal macrophages. Decreased intestinal smooth muscle receptor responses, as observed after an intraperitoneal inflammation, may also be responsible for the observed motility changes observed in intestinal inflammatory disorders.

This work was supported financially by Duphar BV, Weesp, The Netherlands.

1 Parks DA, Bulkley GB, Granger DN, Hamilton SR, McCord $J M$. Ischemic injury in the cat small intestine: role of superoxide radicals. Gastroenterology 1982; 82: 9-15.

2 Younes $M$, Schoenberg $M H$, Jung $H$, Fredholm B, Haglund U, Schildberg FW. Oxidative tissue damage following regional intestinal ischemia and reperfusion in the cat. Res Exp Med 1984; 184: 259-64.

3 Smith SM, Holm-Rutili L, Perry MA, Grisham MB, Arfors K-E, Granger DN, et al. Role of neutrophils in hemorrhagic shock-induced mucosal injury in the rat. Gastroenterology 1987; 93: 466-71.

4 Otamiri T, Tagesson C. Role of phospholipase $A_{2}$ and oxygenated free radicals in mucosal damage after small intestinal ischemia and reperfusion. Am $\mathcal{F}$ Surg 1989; 157 : 562-6.

5 Parks DA, Granger DN. Xanthine oxidase: biochemistry, distribution and physiology. Acta Physiol Scand 1986; 548 (suppl): 87-99.

6 Roldán EJA, Pinus CR, Turrens JF, Boveris A. Chemiluminescence of ischaemic and reperfused intestine in vivo. Gut 1989; 30: 184-7.
7 Grisham MB, Hernandez LA, Granger DN. Xanthine oxidase and neutrophil infiltration in intestinal ischemia. $A m \mathcal{F}$ Physiol 1986; 251: G567-74.

8 Grisham MB, Granger DN. Neutrophil-mediated mucosal injury. Role of reactive oxygen metabolites. Dig Dis $S_{c i}$ 1988; 33: 6-15S.

9 Halliwell B, Hoult JR, Blake DR. Oxidants, inflammation, anti-inflammatory drugs. FASEB $\mathcal{F} 1988 ; 2$ : 2867-73.

10 Suematsu M, Suzuki M, Kitahora T, Miura S, Susuki K, Hibi $\mathrm{T}$, et al. Increased respiratory burst of leukocytes in inflammatory bowel diseases - the analysis of free radical generation by using chemiluminescence probe. $\mathcal{F}$ Clin Lab Immunol 1987; 24: 125-8.

11 Salim AS. The significance of removing oxygen-derived free radicals in the treatment of acute and chronic duodena ulceration in the rat. F Pharm Pharmacol 1990; 42: 64-7.

12 Mayer EA, Raybould H, Koelbel C. Neuropeptides, inflammation, and motility. Dig Dis Sci 1988; 33: 71-7S.

13 Koch TR, Carney JA, Go VLW, Szurszewski JH. Spontaneous contractions and some electrophysiologic properties of circular muscle from normal sigmoid colon and ulcerative colitis. Gastroenterology 1988; 95: 77-84.

14 Burns TW, Mathias JR, Martin JL, Carlson GM, Shields RP. Alteration of myoelectric activity of small intestine by Alteration of myoelectric activity of small intestine by
invasive Escherichia Coli. Am $\mathrm{F}$ Physiol 1980; 238: G57-62.

15 Sjogren RW, Sherman PM, Boedeker EC. Altered intestinal motility precedes diarrhea during Escherichia coli enteric infection. Am $\mathcal{F}$ Physiol 1989; 257: G725-31.

16 Scott RB, Gall DG, Diamant SC. Intestinal motility during acute Yersinia enterocolitica enteritis in rabbits. Can F Physiol Pharmacol 1989; 67: 553-60.

17 Smith JW, Castro GA. Relation of peroxidase activity in gut mucosa to inflammation. Am f Physiol 1978; 234: R72-9.

18 Van der Vliet A, Tuinstra TJR, Bast A. Modulation of oxidative stress in the gastrointestinal tract and effect on intestinal motility. Biochem Pharmacol 1989; 38: 280718.

19 Van der Vliet A, Tuinistra TJR, Rademaker B, Bast A Intestinal motility disorder induced by peroxides: possible Intestinal motility disorder induced by peroxides: possible
role of lipid peroxidation. Res Commun Chem Pathol role of lipid peroxidation.
Pharmacol 1990; 70: $227-43$.

20 Haenen GRMM, Van Dansik P, Vermeulen NPE, Timmerman J, Bast A. The effect of hydrogen peroxide on $\beta$-adrenoceptor function in the heart. Free Radic Res Commun 1988; 4: 243-9.

21 Van der Vliet A, Bast A. Hydrogen peroxide reduces the betaadrenoceptor function in the rat small intestine. Eur $f$ Pharmacol 1991; 199: 153-6.

22 Goris RJA, Boekholtz WKF, Van Bebber IPT, Nuytinck JKS, Schillings PHM. Multiple-organ failure and sepsis without bacteria. An experimental model. Arch Surg 1986; 12: 897-901.

23 Forrest MJ, Jose PJ, Williams TJ. Kinetics of the generation and action of chemical mediators in zymosan-induced inflammation of the rabbit peritoneal cavity. $\mathrm{Br} \mathcal{F}$ Pharmaco 1986; 89: 719-30.

24 Doherty NS, Poubelle P, Borgeat P, Beaver TH, Westrich GL, Schrader NL. Intraperitoneal injection of zymosan in mice induces pain, inflammation and the synthesis of peptidoleukotrienes and prostaglandin $\mathrm{E}_{2}$. Prostaglandin 1985; 30: 769-89.

25 Van der Vliet A, Rademaker B, Bast A. A beta-adrenoceptor with atypical characteristics is involved in the relaxation of with atypical characteristics is involved in the relaxation of
the rat small intestine. $\mathcal{F}$ Pharmacol Exp Ther 1990; 255: the rat sma 26.

26 Hissin PJ, Hilf R. A fluorometric method for determination of oxidized and reduced glutathione in tissues. Anal Biochem 1976; 74: 241-26.

27 Haenen GRMM, Bast A. Protection against lipid peroxidation by a microsomal glutathione-dependent labile factor. FEBS Lett 1983; 159: 24-8.

28 Krawisz JE, Sharon P, Stenson WF. Quantitative assay for acute intestinal inflammation based on myeloperoxidase activity. Gastroenterology 1984; 87: 1344-50.

29 Suzuki K, Ota H, Sasagawa S, Sakatani T, Fujikura T. Assay method for myeloperoxidase in human polymorphonuclear leukocytes. Anal Biochem 1983; 132: 345-52.

30 Bradford MM. A rapid and sensitive method for the quantitation of microgram quantities of protein using the principle of tion of microgram quantities of protein using the princip
protein dye binding. Anal Biochem 1976; 72:248-54.

31 Pick E, Keisari Y. A simple colorimetric method for the measurement of hydrogen peroxide produced by cells in measurement of hydrogen peroxide produced
culture. F Immunol Methods 1980; 38: 161-70.

32 Roos D, Bot AAM, Van Schaik MLJ, De Boer M, Daha MR Interaction between human neutrophils and zymosan particles: the role of opsonins and divalent dications. f Immunol 1981; 126: 433-40.

33 Bhatnagar R, Schirmer R, Ernst M, Decker K. Superoxide release by zymosan-stimulated rat Kupffer cells in vitro. Eur F Biochem 1981, 119: 171-5.

34 Raaijmakers JAM, Beneker C, Van Geffen ECG, Meisters THM, Pover $P$. Inflammatory mediators and $\beta$ adrenoreceptor function. Agents Actions 1989; 26: 45-7. 